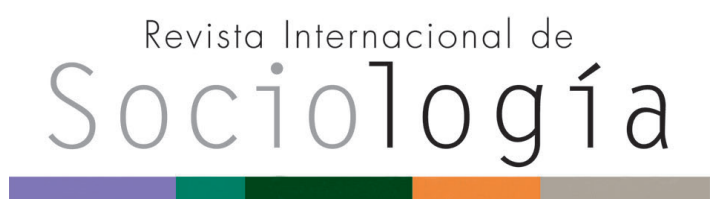

Revista Internacional de Sociología RIS

vol. 77 (3), e137, julio-septiembre, 2019, ISSN-L:0034-9712 https://doi.org/10.3989/ris.2019.77.3.18.028

\section{EFECTOS DEL ORIGEN SOCIAL Y DE LA POSICIÓN DE CLASE EN EL BIENESTAR MATERIAL. UN ABORDAJE SOBRE LA DESIGUALDAD SOCIAL EN LA CIUDAD DE BUENOS AIRES 2012-2013}

\author{
JosÉ JAVIER RODRÍGUEZ DE LA FUENTE \\ Instituto de Investigaciones Gino Germani. Universidad Buenos Aires \\ jrodriguez@conicet.gov.ar \\ ORCID iD: https://orcid.org/0000-0002-5150-7261
}

Cómo citar este artículo / Citation: Rodríguez de la fuente, J.J. 2019. "Efectos del origen social y de la posición de clase en el bienestar material. Un abordaje sobre la desigualdad social en la Ciudad de Buenos Aires 2012-2013". Revista Internacional de Sociología 77(3):e137. https://doi.org/10.3989/ris.2019.77.3.18.028

\section{Resumen}

Este artículo indaga en qué medida la posición de clase, tanto de origen como de destino, explica desiguales condiciones de vida, medidas a partir del acceso a determinados niveles de bienestar material. Se exploran, de este modo, tres aristas de la desigualdad social: las condiciones, las oportunidades y los resultados.

En este sentido, se elaboran modelos explicativos que permitan comprender cómo determinadas condiciones de origen e individuales intervienen en el acceso a tres activos centrales que configuran el bienestar de los hogares: el nivel de ingresos laborales, la propiedad de la vivienda y el nivel de consumo material.

La metodología asumida es de índole cuantitativa, utilizándose técnicas de regresión lineal múltiple y regresión logística binomial. La fuente de datos que se utiliza proviene de la Encuesta sobre movilidad social y opiniones sobre la sociedad actual del año 2012-2013, realizada en la Ciudad Autónoma de Buenos Aires.

\section{Palabras Clave}

Condiciones de vida; Consumo; Estratificación social; Ingresos; Movilidad social; Vivienda.

\section{EFFECTS OF SOCIAL ORIGIN AND CLASS POSITION ON MATERIAL WELL-BEING. AN APPROACH ON SOCIAL INEQUALITY IN THE CITY OF BUENOS AIRES 2012-2013}

Copyright: (c) 2019 CSIC. Este es un artículo de acceso abierto distribuido bajo los términos de la licencia de uso y distribución Creative Commons Reconocimiento 4.0 Internacional (CC BY 4.0).

Recibido: 16/02/2018. Aceptado: 17/01/2019. Publicado online: 24/09/2019

\section{Abstract}

This article explores to what extent the class position, both of origin and destination, explains unequal living conditions, measured by access to certain levels of mate-rial well-being. In this way, three edges of social inequal-ity are explored: conditions, opportunities and results.

Explanatory models will be developed to understand how certain conditions of origin and individuals inter-vene in the access to three central assets that shape the wellbeing of households: level of labour income, home-ownership and level of material consumption.

The assumed methodology is of a quantitative nature, using multiple linear regression and binomial logistic re-gression techniques. The source of data comes from the Survey on social mobility and opinions on current society of the year 2012-2013 conducted in the Ciudad Autónoma de Buenos Aires.

\section{KEYWORDS}

Consumption; Home-ownership; Income; Life condi-tions; Social mobility; Social stratification. 


\section{INTRODUCCIÓN}

La bibliografía especializada en la temática ha demostrado que, en las sociedades modernas y a lo largo de la historia contemporánea, la asociación entre los orígenes y los destinos de clase, medidos intergeneracionalmente, ha prevalecido (Erikson y Goldthorpe 2002, 1992; Hout y DiPrete 2006) por sobre la existencia de una estructura social abierta, orientada por la igualdad de oportunidades (Kerbo 1998). Sin embargo, es válido preguntarse qué sucede más allá del posicionamiento de clase, es decir, en qué medida los efectos de origen y de posición persisten cristalizándose en desigualdades de resultados (control de recursos y activos) que se reproducen en desigualdades de condiciones de las generaciones futuras (Reygadas 2004; Giddens 2001). Si bien ha habido investigaciones que han indagado estas cuestiones, no hay consenso sobre la intensidad y el modo en que los factores adscriptivos condicionan y reproducen la desigualdad social, más allá del efecto que los mismos tienen sobre el logro educativo, la posición en la estructura ocupacional o el nivel de ingresos (Blau y Duncan 1967; Esping-Andersen 2004; Harding et al. 2004; Jencks 1979; Erikson y Jonsson 1998).

Por otra parte, la existencia de barreras o canales que permiten la mejora en los niveles de vida cobra, en estos últimos tiempos, una renovada relevancia a la luz de los debates políticos y académicos en torno a las ideas de la meritocracia, la justicia social y la equidad. De lo que se trata en este paper es de recuperar la tradición, por un lado, del análisis de clase, en tanto factor explicativo central (Carabaña 1997; Dubet 2015; Goldthorpe 2010), pero considerando también el rol que pueden asumir la movilidad social (Erikson y Goldthorpe 2002) y el origen de clase como variables independientes relevantes para comprender los fenómenos anteriormente citados.

Específicamente, se propone: 1) Describir la relación entre la posición de clase de origen, la posición de clase de destino y los distintos aspectos considerados referidos al bienestar material de los hogares (nivel de ingresos, nivel de consumo material y propiedad de la vivienda); 2) Analizar la influencia del origen social y la posición de clase sobre dichos activos del hogar, controlando esa relación según el sexo, la edad y el nivel educativo. El recorte espaciotemporal se efectúa para la Ciudad Autónoma de Buenos Aires (CABA), para los años 2012-2013.

\section{FUNDAMENTOS TEÓRICOS Y ANTECE- DENTES RELEVANTES}

\section{Aportes desde los estudios de movilidad social}

Treiman y Ganzeboom (2000) identificaron cuatro generaciones de estudios en el campo de la movilidad social que se diferencian a partir de los interro- gantes planteados acerca del modo y las técnicas de abordaje. La primera generación se preocupó, a partir de análisis comparativos, de la medida y la forma en que variaban internacionalmente los patrones de movilidad (Glass y Hall 1954; Miller 1960; Lipset y Bendix 1963). La segunda generación se caracterizó por indagar acerca de los factores que explicaban la movilidad social y la distinta fuerza de dichos efectos. Estos interrogantes pudieron traducirse empíricamente a partir de la aplicación de técnicas estadísticas avanzadas, como el path analysis, enmarcadas en lo que se dio a conocer como estudios de "logro de status" (Blau y Duncan 1967). En la tercera generación de estudios sobre movilidad social se plantean ciertas rupturas con las anteriores, principalmente al partir de enfoques no funcionalistas. Se retomó el interrogante por la movilidad social comparada, pero a partir de técnicas estadísticas más sofisticadas (modelos log-lineales) y se intentaron superar dos de las críticas que se le habían realizado a las generaciones anteriores: ateoricismo e ininterpretabilidad de los resultados (Cachón Rodríguez 1989: 325). Dentro de esta generación, es central el papel del grupo del Nuffield College (Universidad de Oxford), con John Goldthorpe como máximo representante ${ }^{1}$. Finalmente, la cuarta generación adquiere un carácter ecléctico; sin embargo, los autores especifican algunas de sus principales características: la profundización del uso de nuevas fuentes secundarias que permiten la comparación temporal y entre diversos países; la expansión de nuevos proyectos internacionales de investigación; el avance en el uso de diseños multinivel que permiten relacionar la información a nivel micro con aquella de nivel macro; el avance en el uso de análisis multivariados que permiten el uso de variables categóricas, y la estandarización de esquemas de medición (EGP, ISEI, SIOPS).

En Argentina, los estudios de estratificación y movilidad social cobraron importancia simultáneamente a sus desarrollos a nivel internacional. Pueden considerarse los aportes de Germani al análisis de la estructura social argentina (1955) y de la movilidad social en Buenos Aires (1963), así como los estudios empíricos realizados por Rubinstein (1973) y Beccaria (1978), entre otros. Hacia finales de los años setenta y hasta principios del nuevo siglo, la temática del análisis de clase y, por ende, de la movilidad social, quedó opacada y postergada por otros temas que ganaron trascendencia en la agenda académica y política: pobreza, vulnerabilidad, informalidad, etc. Sin embargo, en este impase pueden nombrarse los valiosos aportes de Torrado (1992), continuadores del legado de Germani en el análisis de la estructura de clase, principalmente en el intento relacionar los estilos de desarrollo y las trasformaciones morfológicas de las clases sociales, así como las continuas mediciones y análisis de movilidad social realizados por Jorrat $(1987,2000)$. Es recién entrada la década de los dos mil que el debate por las clases sociales y la movilidad vuelve a 
ganar terreno en el país y en la región, principalmente debido al interés de indagar las repercusiones que las transformaciones sobre el modelo de acumulación tuvieron sobre la estructura social y su dinámica. En esta nueva ola de aportaciones, pueden citarse los trabajos de Kessler y Espinoza (2007), Dalle (2016), Chávez Molina (2013), Gómez Rojas (2009), QuartuIli y Salvia (2012), Pla (2016), Riveiro (2011), Benza (2012), Fachelli (2013), entre otros.

Ahora bien, ¿cuáles fueron los principales resultados a los que se arribó? En este sentido, pueden listarse algunas de las principales contribuciones empíricas (Hout y DiPrete 2006; Erikson y Goldthorpe 2002): 1) existencia de un régimen endógeno de movilidad común para todos los países modernosindustrializados, más allá de algunas diferencias, entre países y en el tiempo, en cuanto a la fuerza de la relación entre los orígenes y los destinos; 2) la educación continúa siendo el principal factor explicativo tanto de la movilidad ascendente como de la reproducción de determinadas posiciones; 3) sin embargo, aún controlados los efectos del nivel educativo, la clase de origen continúa mostrando su condicionamiento sobre otros resultados, evidenciando cierto distanciamiento del ideal meritocrático.

\section{Más allá de la posición de clase. Efecto de la clase y los orígenes sociales sobre el bienes- tar material}

Como se ha indicado hasta aquí, hay un consenso en la comunidad académica vinculado a los estudios sobre estratificación y movilidad social acerca de la asociación entre los factores adscriptivos, el logro educativo y la posición de clase alcanzada. En cambio, el estudio de la distribución de activos y bienes (valorados socialmente) en función de la división del trabajo y los procesos de movilidad social se presenta como una temática poca abordada (Torche y Spilerman 2009: 75; 2006: 29).

En América Latina hubo aproximaciones a la problemática acerca del modo en que diversos factores adscriptivos (incorporando la medición del nivel de riqueza en el hogar) y el posicionamiento socio-ocupacional, entre otros, influyen sobre el logro educativo, los niveles de consumo material, la posesión de activos financieros y el acceso a la propiedad de la vivienda (Torche y Spilerman 2009; Torche y Costa Ribeiro 2012; Behrman y Vélez-Grajales 2015; ReyesHernández, Cerón-Vargas, y López-López 2016).

En trabajos anteriores (Rodríguez de la Fuente 2016; Rodríguez de la Fuente y Fernández Melián 2015) se ha evaluado el impacto del posicionamiento de clase y de diversos aspectos adscriptos en relación con la distribución de la riqueza y el bienestar en los hogares, a partir de abordajes de tipo exploratorio, llegando a resultados preliminares que remarcan la importante influencia del posicionamiento en la estructura de clases sobre los niveles de bienestar material de los hogares, aunque relativizando el impacto directo de los efectos de origen.

La discusión en torno a qué es el bienestar y cómo medirlo es un debate que recorre las diversas disciplinas de las ciencias sociales y la filosofía (Sen 1992; Rawls 1995; Roemer y Trannoy 2016; Boltvinik 2014; Pena-Trapero 2009; Spilerman 2000). Particularmente, en este trabajo se consideraran tres aspectos constitutivos del bienestar material de los hogares: el nivel de ingresos laborales, la propiedad de la vivienda y el nivel de consumo. A continuación, se presenta un breve repaso de antecedentes sobre estudios desde el campo de la estratificación que han observado dicha problemática.

En primer lugar, pueden situarse aquellos trabajos que han estudiado el par estratificación-nivel de ingresos. Tempranamente, desde el estructural-funcionalismo, la posición ocupacional y el nivel de ingresos se erigieron como las propiedades centrales que determinaban el nivel de status de un sujeto o un hogar (Cachón Rodríguez 1989; Parsons 1954). Por su lado, desde un enfoque marxista, también la estructura de clases fue estudiada a partir de la percepción de los ingresos (Wright 1979). Recientemente, algunos aportes empíricos refuerzan la interconexión entre ambos aspectos bajo estudio. Weeden et al. (2007), para Estados Unidos, indican que, tanto desde un abordaje basado en grandes clases (esquema EGP) como a partir de micro-clases, la proporción de varianza explicada en los ingresos por dicha variable independiente ha aumentado sostenidamente desde principios de los años 80. Por otro lado, para el caso italiano, Albertini (2013) señala que, entrado el siglo XXI, la clase social explicaba un $17 \%$ de la desigualdad del ingreso, demostrando que el vínculo entre ambos aspectos continúa manteniendo su fuerza, sobre todo al intensificarse la diferenciación entre la alta y baja clase de servicio. En el estudio de la Argentina reciente, Benza (2016) encuentra que, entre 2003 y 2010 , las clases populares han aumentado sus ingresos en un $77 \%$, reduciéndose las distancias que las separan de las clases medias, debilitando la barrera manual-no manual. Por su parte, Chávez Molina y Sacco (2015), a partir de un estudio que aborda el reciente desarrollo de la estructura de clases desde la óptica de la heterogeneidad estructural, señalan que la mayor recomposición, en términos de ingresos monetarios, se ha dado para aquellos grupos ligados a los grandes establecimientos.

El estudio de la movilidad social y su vinculación a la distribución del ingreso fue abordado desde una perspectiva tributaria al logro de estatus, indagándose cómo determinados factores adscriptivos y ligados al capital humano tienen efectos sobre la percepción de los ingresos (Harding et al. 2004; Jencks 1979; Hauser y Sewell 1986). Para el caso argentino, Rubinstein (1973) realizó un análisis pionero, al poner en juego el 
modo en que la percepción de los ingresos individuales y familiares variaba en función de la trayectoria de movilidad experimentada a lo largo de tres generaciones. Más recientemente, puede hablarse de los aportes de Pla (2016) y Quartulli y Salvia (2012), a partir de los cuales se indaga cómo los ingresos se distribuyen en una tabla de movilidad, concluyendo que a igual posición de clase, el origen social tiene influencia en el nivel de ingreso percibido.

La relación entre estructura de clase-acceso a la propiedad de la vivienda ha sido poco estudiada, con algunas excepciones de la sociología y la economía urbana europeas (Saunders 1978; Kurz 2004; Kurz y Blossfeld 2004; Savage, Watt, y Arber 1992; Spilerman y Wolff 2012). Sin embargo, los housing studies (Kemeny 2013) sí han abordado el problema de la vivienda desde diversas aristas de la desigualdad y, en ese sentido, existe una tradición consolidada que presenta diferentes líneas de investigación.

Como dimensión del bienestar material, la posesión de una vivienda resulta significativa en, al menos, dos aspectos: por un lado, es una fuente de "seguridad ontológica" (Giddens 1994) y, por el otro, brinda un potencial de acumulación patrimonial (Saunders 1984: 2; Bourdieu 2000). En parte, esta falta de investigaciones desde el campo de la estratificación social deviene de la presunción de consistencia, anteriormente tratada, por la cual se supone que no es necesario estudiar los activos del hogar porque los mismos se corresponden con la posición de clase, la ocupación y el nivel de ingresos (Kurz y Blossfeld 2004: 3). Como bien indican estos autores, aunque la clase social no tenga un efecto directo sobre las posibilidades de acceso a la vivienda, aún tiene un efecto indirecto vía transferencias intergeneracionales de recursos y la socialización en torno a la idea imperante de propiedad (Kurz y Blossfeld 2004: 374; Lersch y Luijkx 2015). En la región, la investigación de esta temática es más acotada aún y se engloba en el análisis conjunto de la distribución de la riqueza de los hogares (Torche y Spilerman 2009; Behrman y Vélez-Grajales 2015).

Finalmente, respecto a la relación estratificaciónmovilidad social-consumo material, ya en el clásico libro Movilidad social en la sociedad industrial (Lipset y Bendix 1963), los autores remarcaban la importancia de analizar el modo en que el ambiente cultural y las aspiraciones sociales de la familia influyen sobre la forma en que los ingresos son gastados, generándose particulares pautas de consumo (Lipset y Bendix 1963: 295). De forma resumida, puede indicarse que dos líneas de investigación se han abierto en el estudio de la relación clase-consumo (Del Cueto y Luzzi 2016: 210): aquellas tributarias de las contribuciones de Bourdieu (Warde y Gayo-Cal 2009; Van Eijck 1999; Herrera-Usagre 2013; Le Roux et al. 2008), que centran su atención en la transmisión de aptitudes culturales y los procesos de (des)diferenciación entre las clases sociales; y aquellas que incorporan el consumo como un elemento más a considerar en el estudio de las condiciones de vida y el bienestar de los hogares (Pla 2014; Torche y Spilerman 2009). Esta segunda línea presenta un menor desarrollo y este trabajo intenta contribuir en esa dirección.

\section{La especificidad del estudio de la estratifica- ción y la movilidad social en la CABA}

Como bien se ha señalado en los apartados anteriores, los estudios referidos a la temática en Argentina, estuvieron circunscriptos a todo el país o, en la mayor parte de los casos, al Aglomerado Gran Buenos Aires (AGBA). Dicha aglomeración contiene a la CABA y se define como el área geográfica delimitada por la "envolvente de población" o lo que también puede llamarse "mancha urbana" (INDEC 2003: 4). Por su parte, la ciudad, en tanto capital del conjunto nacional, dispone de cierta densidad política, económica y social que la diferencia de otras ciudades y regiones del país, específicamente respecto al nivel de vida (Velázquez 2007). Comparativamente, dispone de un notable desarrollo en aquellas actividades terciarias de mayor dinamismo (actividades científicas y profesionales, información y comunicación, actividades financieras, enseñanza, etc.), al mismo tiempo que presenta una población ocupada con altos niveles educativos ${ }^{2}$. Ambos elementos permiten la caracterización de la misma como una "ciudad global" (Sassen 1998), así como una "ciudad de clases medias" en donde las mismas pueden llegar a explicar el $70 \%$ de la población residente (Benza 2016: 124).

En este contexto, la ausencia de estudios en la temática que hayan considerado la ciudad como espacio específico a ser investigado ha originado la inquietud inicial de las indagaciones propuestas en este artículo. Así mismo, resulta relevante preguntarse en qué medida la asociación entre los procesos de estratificación y movilidad presentan una ligazón más o menos fuerte con la distribución del bienestar material en una ciudad en la que, como hemos señalado, prima cierto dinamismo del mercado de trabajo (de servicios) y en donde se ostentan altas tasas de población con niveles educativos superiores. A modo de hipótesis, y siguiendo los estudios internacionales anteriormente reseñados, puede postularse que las características propias de la ciudad posibilitarían un cierto debilitamiento en la relación entre el origen y el destino de clase respecto al acceso a mejores niveles de bienestar ${ }^{3}$.

\section{Metodología Y FUENTES de dATOS}

El abordaje metodológico en este trabajo es de tipo cuantitativo, utilizando como fuente de datos la Encuesta sobre movilidad social y opiniones sobre la sociedad actual del año 2012-20134. La muestra es probabilística, estratificada, proporcional y consta de 700 casos. 
El universo de análisis estuvo conformado por personas mayores de 30 años ocupadas que residían en la Ciudad Autónoma de Buenos Aires. La generación de hijos e hijas está comprendida por individuos nacidos entre el año $1932^{5}$ y el año 1983. Por su parte, la encuesta recabó información sobre los orígenes sociales a partir de preguntas retrospectivas que se realizaron a las personas encuestadas acerca de la posición del padre, la madre o el principal sostén del hogar cuando los mismos tenían alrededor de 16 años.

Para la clasificación de las posiciones de clase de origen y de destino se ha partido del "nomenclador de la condición socio-ocupacional" (CSO) elaborado por Torrado (Torrado 1992; 1998; Sacco 2016). El mismo define estratos socio-ocupacionales que permiten el estudio de la estructura de clases a partir del posicionamiento de los agentes en los procesos de producción económica y de las diferentes condiciones de vida (Torrado 1998: 224). Dicho nomenclador puede agregarse hasta conformar una estructura tripartita de clases (alta, media y obrera). Este trabajo no sigue dicha modalidad de agregación, ya que se propone un sistema clasificatorio de cinco clases (ver esquema 1), siguiendo la propuesta de Pla (2016), pero planteando algunas innovaciones.

Para el estudio de la interacción entre la posición de clase de origen y de destino proponemos una tipología de trayectorias intergeneracionales, utilizada en otros escritos (Rodríguez de la Fuente 2016, 2014; Rodríguez de la Fuente y Fernández Melián 2015), que identifica los siguientes movimientos: herencia en la cúspide (clase directiva-profesional), ascenso a la cúspide, descenso a la clase media (pequeña burguesía y clase media técnica rutinaria), herencia en la clase media, ascenso a la clase media, descenso a la clase trabajadora y herencia en la clase trabajadora.

Para el análisis de regresión se han presentado los ingresos laborales de la persona encuestada con una transformación logarítmica (In) a los fines de facilitar la lectura ${ }^{6}$ y normalizar la distribución de la variable (Jencks 1979: 8-9). La propiedad de la vivienda se ha categorizado de manera dicotómica: propietario/no propietario. En el caso del nivel de consumo, se ha construido un índice factorial, basado en la tenencia de ciertos bienes de equipamiento del hogar y de automóvil (Filmer y Pritchett 2001; Minujin y Bang 2002; Torche y Spilerman 2009; Behrman y VélezGrajales 2015; McKenzie 2005). Sin embargo, a diferencia de estos trabajos, se ha utilizado la técnica de análisis de correspondencias múltiples, ya que se adecuaba de mejor forma a la naturaleza de las variables tratadas (Baranger 2009: 104-110). Construido a partir del primer factor emergente (aquel que explica la mayor proporción de la varianza), el índice permite no solo puntuar, en forma ponderada a través de los valores propios, a los sujetos en función de los bienes que poseen en el hogar, sino también a partir de aquellos de los cuales están privados o no poseen. En anexo se presentan las coordenadas y contribuciones para el primer factor de cada uno de los bienes considerados ${ }^{7}$.

Esquema 1.

Esquema de clases sociales. Modalidad desagregada y agregada

\begin{tabular}{|c|c|}
\hline Estratos (CSO) & Clases sociales \\
\hline Directores de empresas & \multirow{2}{*}{ Clase directiva-profesional } \\
\hline Profesionales en función específica & \\
\hline Propietarios de pequeñas empresas & \multirow{2}{*}{ Pequeña burguesía } \\
\hline Pequeños productores autónomos & \\
\hline Cuadros técnicos y asimilados & \multirow{2}{*}{ Clase media rutinaria-técnica } \\
\hline Empleados administrativos y vendedores & \\
\hline Trabajadores especializados autónomos & \multirow{2}{*}{ Clase obrera calificada } \\
\hline Obreros calificados & \\
\hline Obreros no calificados & \multirow{3}{*}{ Clase obrera no calificada } \\
\hline Peones autónomos & \\
\hline Empleados domésticos & \\
\hline
\end{tabular}

Fuente: elaboración propia con base en Torrado (1998). 


\section{Resultados}

\section{Análisis descriptivo}

En primer lugar, antes de indagar la influencia que las posiciones de clase de destino y de origen tienen sobre los diversos aspectos del bienestar material, recurrimos al análisis descriptivo (cuadros 1 y 2 ).
Con respecto a la medición de la estructura de clases, comparando los orígenes y los destinos puede observarse la pérdida intergeneracional en el peso de la clase trabajadora calificada y la pequeña burguesía y el crecimiento de la clase media técnicarutinaria y la clase directiva profesional. Por su parte, las diferencias entre el nivel educativo de origen y de destino dan cuenta del incremento de las titulacio-

\section{Cuadro 1.}

Estadísticas descriptivas de las variables categóricas. CABA 2012-2013.

\begin{tabular}{|c|c|c|}
\hline Clase social de destino & Frecuencia & $\%$ \\
\hline Clase directiva-profesional & 118 & 16,9 \\
\hline Pequeña burguesía & 104 & 14,9 \\
\hline Clase media rutinaria-técnica & 208 & 29,7 \\
\hline Clase obrera calificada & 175 & 25 \\
\hline Clase obrera no calificada & 95 & 13,6 \\
\hline Total & 700 & 100 \\
\hline \multicolumn{3}{|l|}{ Clase social de origen } \\
\hline Clase directiva-profesional & 92 & 13,4 \\
\hline Pequeña burguesía & 139 & 20,2 \\
\hline Clase media rutinaria-técnica & 146 & 21,2 \\
\hline Clase obrera calificada & 237 & 34,4 \\
\hline Clase obrera no calificada & 74 & 10,8 \\
\hline Total & 688 & 100 \\
\hline \multicolumn{3}{|l|}{ Trayectoria intergeneracional } \\
\hline Herencia en la cúspide & 34 & 4,94 \\
\hline Ascenso a la cúspide & 82 & 11,92 \\
\hline Descenso a la clase media & 47 & 6,83 \\
\hline Herencia en la clase media & 154 & 22,38 \\
\hline Ascenso a la clase media & 108 & 15,7 \\
\hline Descenso a la clase trabajadora & 80 & 11,63 \\
\hline Herencia en la clase trabajadora & 183 & 26,6 \\
\hline Total & 688 & 100 \\
\hline \multicolumn{3}{|l|}{ Nivel educativo de destino } \\
\hline Hasta primario completo & 97 & 13,9 \\
\hline Hasta secundario completo & 256 & 36,6 \\
\hline Hasta universitario completo & 347 & 49,6 \\
\hline Total & 700 & 100 \\
\hline \multicolumn{3}{|l|}{ Nivel educativo de origen } \\
\hline Hasta primario completo & 319 & 45,6 \\
\hline Hasta secundario completo & 258 & 36,9 \\
\hline Hasta universitario completo & 123 & 17,6 \\
\hline Total & 700 & 100 \\
\hline \multicolumn{3}{|l|}{ Propiedad de la vivienda } \\
\hline No propietario & 306 & 43,71 \\
\hline Propietario & 394 & 56,29 \\
\hline Total & 700 & 100 \\
\hline
\end{tabular}

Fuente: elaboración propia con base en la Encuesta FONCYT 2012-2013. 
Cuadro 2.

Estadísticos descriptivos de las variables continuas. CABA 2012-2013

\begin{tabular}{lccccc}
\hline Variable & Obs & Media & Std. Dev. & Min & Max \\
\hline Ingresos laborales & 700 & 5572,83 & 4499,17 & 0 & 24000 \\
Ln (ingresos laborales) & 694 & 8,34 & 0,81 & 5,99 & 10,09 \\
Índice de consumo & 700 & 0,56 & 0,14 & 0,00 & 1,00 \\
\hline
\end{tabular}

$\mathrm{N}=700$. Fuente: elaboración propia con base en la Encuesta FONCYT 2012-2013.

nes, tanto en el nivel secundario como en el terciariouniversitario. El acceso a la vivienda a través de la propiedad es alcanzado por el $56 \%$ de las personas encuestadas, replicándose tendencias similares a las encontradas en países con regímenes de bienestar social-demócratas (p. ej.: Holanda, Dinamarca) (Kurz y Blossfeld 2004: 366-367).

Centrando el análisis en la posición de clase (origen y destino) resulta relevante evaluar si ambos aspectos se vinculan con el nivel de ingresos, la propiedad de la vivienda y el nivel de consumo. En los cuadros siguientes exploramos dichas relaciones.
Con respecto al nivel de ingresos (cuadro 3), tanto según la clase de origen como del hijo o hija puede encontrarse asociación entre las variables. Sin embargo, observando el valor $F$, producto del análisis de la varianza, la relación clase de destino-ingresos es más fuerte. En dicho caso los ingresos se distribuyen en forma escalonada y polarizada, apropiándose la clase superior aproximadamente de tres veces más de ingresos respecto a la clase trabajadora no calificada. La relación clase de origen-ingresos no presenta una polarización tan marcada, indicando de este modo que la desigualdad de ingresos se amplifica específicamente a partir de la posición de destino ocupada por los sujetos.

\section{Cuadro 3.}

Nivel de ingresos según la clase social de origen y del hijo o hija. CABA 2012-2013

\begin{tabular}{lcccc}
\hline \multirow{2}{*}{ Clase social } & \multicolumn{2}{c}{ Destino } & \multicolumn{2}{c}{ Origen } \\
\cline { 2 - 5 } & Media & SD & Media & SD \\
\hline Clase directiva-profesional & 9134,75 & 6089,31 & 6677,17 & 5557,85 \\
Pequeña burguesía & 6440,39 & 5295,09 & 6427,34 & 4910,28 \\
Clase media rutinaria-técnica & 5601,20 & 3428,75 & 6401,71 & 5055,73 \\
Clase obrera calificada & 4176,91 & 2630,83 & 4546,41 & 3176,87 \\
Clase obrera no calificada & 2708,11 & 2503,77 & 4269,32 & 3383,83 \\
Total & 5572,83 & 4499,17 & 5575,26 & 4474,03 \\
\hline
\end{tabular}

Destino: $F=40,90 \quad p=0,000$

Origen: $F=9,01 \quad p=0,000$

$\mathrm{N}($ clase destino $)=700 ; \mathrm{N}$ (clase origen $)=688$

Fuente: elaboración propia con base en la Encuesta FONCYT 2012-2013.

\section{Cuadro 4.}

Propiedad de la vivienda según la clase social de origen y del hijo o hija. CABA 2012-2013

\begin{tabular}{lcc}
\multicolumn{1}{c}{ Clase social } & $\begin{array}{c}\text { Propietarios } \\
\text { destino }\end{array}$ & $\begin{array}{c}\text { Propietarios } \\
\text { origen }\end{array}$ \\
\hline Clase directiva-profesional & 70,34 & 56,52 \\
Pequeña burguesía & 66,35 & 63,31 \\
Clase media rutinaria-técnica & 57,69 & 59,59 \\
Clase obrera calificada & 43,43 & 54,01 \\
Clase obrera no calificada & 48,42 & 41,89 \\
\hline
\end{tabular}

Destino: Pearson chi2(4) $=28,0621 \mathrm{Pr}=0,000$ Cramér's $V=0,200$

Origen: Pearson chi2(4) $=10,1486 \mathrm{Pr}=0,038$ Cramér's $V=0,121$

$\mathrm{N}($ clase destino $)=700 ; \mathrm{N}$ (clase origen $)=688$.

Fuente: elaboración propia con base en la Encuesta FONCYT 2012-2013. 
Cuadro 5.

Nivel de consumo según la clase social de origen y de hijo o hija. CABA 2012-2013

\begin{tabular}{lcccc}
\hline \multicolumn{1}{c}{ Clase social } & \multicolumn{2}{c}{ Destino } & \multicolumn{2}{c}{ Origen } \\
\cline { 2 - 5 } & Media & SD & Media & SD \\
\hline Clase directiva-profesional & 0,63 & 0,11 & 0,60 & 0,12 \\
Pequeña burguesía & 0,60 & 0,14 & 0,61 & 0,13 \\
Clase media rutinaria-técnica & 0,58 & 0,13 & 0,58 & 0,15 \\
Clase obrera calificada & 0,51 & 0,14 & 0,53 & 0,14 \\
Clase obrera no calificada & 0,48 & 0,15 & 0,51 & 0,14 \\
Total & 0,56 & 0,14 & 0,56 & 0,14 \\
\hline
\end{tabular}

Destino: $F=27,32 p=0,000$

Origen: $F=12,52 p=0,000$

$\mathrm{N}($ clase destino $)=700 ; \mathrm{N}$ (clase origen $)=688$

Fuente: elaboración propia con base en la Encuesta FONCYT 2012-2013.

El acceso a la propiedad de la vivienda (cuadro 4) presenta una menor intensidad de asociación respecto a las variables de posicionamiento de clase, aunque para la clase del hijo o hija esta relación se muestra más fuerte $(\mathrm{V}$ de Cramer $=0,205)$. Torche y Spilerman (2009: 80; 2006) aclaran que la relación entre nivel de ingresos y tenencia de la vivienda es baja en la mayoría de los países latinoamericanos, dado que la propiedad de la vivienda se distribuye de forma más homogénea a lo largo de la estratificación. Este resultado se replicaría, en este caso, considerando la posición de clase. De todas maneras, el porcentaje de propietarios según clase social de destino asciende a un mejor posicionamiento en la estructura social.

El nivel de consumo (cuadro 5) también parece comportarse en forma conservadora al evaluarlo en función del posicionamiento de clase de origen y de destino. Si bien para ambos casos puede sostenerse que a mejor posición de clase, mayor nivel de consumo y el estadístico $\mathrm{F}$ da cuenta de cierta capacidad explicativa, las puntuaciones medias entre la clase mejor y peor posicionada no presentan una distancia considerable, principalmente en el caso de la clase de origen.

\section{Análisis multivariable}

El análisis descriptivo permitió una primera aproximación al estudio del bienestar material enfocándose en el posicionamiento que los individuos ocupan en la estructura de clases y sus orígenes sociales. En este sub-apartado se intentará no solo dar cuenta de cuánto influyen ambas variables en el nivel de ingresos, el acceso a la propiedad de la vivienda y el nivel de consumo, sino que también serán incorporadas nuevas variables para especificar y controlar dicha relación planteada. Para cada una de las variables dependientes se pondrán a prueba tres modelos anidados: el primero evalúa únicamente la influencia de la posición de clase y el nivel educativo de origen, es decir, aquellos factores adscriptos; el segundo agrega la posición de clase y el nivel educativo del hijo o hija; el tercero y último agrega, a su vez, un control por edad y sexo del hijo o hija. A su vez, se agrega un cuarto modelo no anidado ${ }^{8}$ que incorpora la variable 'trayectoria', de modo que se pueda indagar específicamente el efecto derivado de los posibles canales de movilidad social.

Para el análisis multivariable respecto al nivel de ingresos se plantea una regresión lineal múltiple (cuadro 6). Los coeficientes son presentados en su forma exponencial para facilitar la lectura.

En primera instancia, observando las medidas de bondad de ajuste de los modelos, es destacable la mejora considerable generada al incorporar las variables que dan cuenta de la posición de clase y el nivel educativo de los hijos e hijas (el $\mathrm{R}^{2}$ aumenta en aproximadamente 16 puntos). Por su parte, la incorporación del control por sexo y edad también produce una mejora relevante, aunque menor respecto al modelo 2 . Los coeficientes del primer modelo muestran una tendencia esperada, si bien no con tanta fuerza, los orígenes de clase mejores posicionadas frente a los orígenes de clase trabajadora, perciben un mayor porcentaje de ingresos. EI nivel educativo también sigue dicha tendencia. De este modo, reteniendo el tercer modelo para simplificar el análisis puede indicarse que la posición de clase de destino es la que en mayor medida explica las desigualdades en la distribución del ingreso. La clase directiva-profesional se apropia, en promedio, de un $150 \%$ más de ingreso que la clase trabajadora no calificada, aun controlando por nivel educativo, edad y sexo. Así mismo, la incorporación de estas dos últimas variables resulta de una gran relevancia, ya que cada año adicional ${ }^{9}$ para el hijo o hija brinda mayores probabilidades de percibir mejores ingresos, situación que se torna drásticamente a la inversa cuando se trata de las mujeres. El modelo 4 , que incorpora la variable trayectoria (aunque retirando las variables de posición de clase), no pre- 


\section{Cuadro 6.}

Regresión lineal múltiple. Variable dependiente: Ln (ingresos laborales de la persona encuestada) CABA 2012-2013

\begin{tabular}{|c|c|c|c|c|}
\hline & Mod. 1 & Mod. 2 & Mod. 3 & Mod. 4 \\
\hline \multirow[t]{2}{*}{ Clase directiva-profesional (origen) } & $1,346^{* *}$ & 0,904 & 0,869 & \\
\hline & $(0,181)$ & $(0,117)$ & $(0,106)$ & \\
\hline \multirow[t]{2}{*}{ Pequeña burguesía (origen) } & $1,489^{* * *}$ & 1,077 & 1,024 & \\
\hline & $(0,169)$ & $(0,118)$ & $(0,106)$ & \\
\hline \multirow[t]{2}{*}{ Clase media rutinaria-técnica (origen) } & $1,434^{* * *}$ & 1,082 & 0,975 & \\
\hline & $(0,165)$ & $(0,119)$ & $(0,102)$ & \\
\hline \multirow[t]{2}{*}{ Clase obrera calificada (origen) } & 1,150 & 1,003 & 0,927 & \\
\hline & $(0,120)$ & $(0,0977)$ & $(0,0859)$ & \\
\hline \multirow[t]{2}{*}{ Clase obrera no calificada (origen) } & Ref. & Ref. & Ref. & \\
\hline & $()$. & $()$. & $()$. & \\
\hline \multirow[t]{2}{*}{ Hasta primario completo (origen) } & Ref. & Ref. & Ref. & Ref. \\
\hline & $()$. & $()$. & $()$. & $()$. \\
\hline \multirow[t]{2}{*}{ Hasta secundario completo (origen) } & $1,249^{* * *}$ & 1,019 & 1,074 & 1,113 \\
\hline & $(0,0857)$ & $(0,0702)$ & $(0,0708)$ & $(0,0726)$ \\
\hline \multirow[t]{2}{*}{ Hasta universitario completo (origen) } & $1,339^{* * *}$ & 1,067 & 1,141 & 1,141 \\
\hline & $(0,131)$ & $(0,0998)$ & $(0,102)$ & $(0,103)$ \\
\hline \multirow[t]{2}{*}{ Clase directiva-profesional } & & $3,120^{* * *}$ & $2,588^{* * *}$ & \\
\hline & & $(0,384)$ & $(0,306)$ & \\
\hline \multirow[t]{2}{*}{ Pequeña burguesía } & & $2,097^{* * *}$ & $1,855^{* * *}$ & \\
\hline & & $(0,234)$ & $(0,197)$ & \\
\hline \multirow[t]{2}{*}{ Clase media rutinaria-técnica } & & $2,122^{* * *}$ & $1,997^{* * *}$ & \\
\hline & & $(0,225)$ & $(0,200)$ & \\
\hline \multirow[t]{2}{*}{ Clase obrera calificada } & & $1,734^{\prime * *}$ & $1,466^{* * *}$ & \\
\hline & & $(0,165)$ & $(0,135)$ & \\
\hline \multirow[t]{2}{*}{ Clase obrera no calificada } & & Ref. & Ref. & \\
\hline & & $()$. & $()$. & \\
\hline \multirow[t]{2}{*}{ Hasta primario completo } & & Ref. & Ref. & Ref. \\
\hline & & $()$. & $()$. & $()$. \\
\hline \multirow[t]{2}{*}{ Hasta secundario completo } & & 1,121 & 1,128 & $1,166^{*}$ \\
\hline & & $(0,102)$ & $(0,0966)$ & $(0,101)$ \\
\hline \multirow[t]{2}{*}{ Hasta universitario completo } & & $1,225^{*}$ & $1,317^{* * *}$ & $1,384^{* * * *}$ \\
\hline & & $(0,129)$ & $(0,131)$ & $(0,139)$ \\
\hline \multirow[t]{2}{*}{ Edad } & & & $1,010^{* * *}$ & $1,009^{* * *}$ \\
\hline & & & $(0,00255)$ & $(0,00257)$ \\
\hline Varón & & & $\begin{array}{c}\text { Ref. } \\
\text { (.) }\end{array}$ & $\begin{array}{c}\text { Ref. } \\
\text { (.) }\end{array}$ \\
\hline
\end{tabular}




\begin{tabular}{|c|c|c|c|c|}
\hline & Mod. 1 & Mod. 2 & Mod. 3 & Mod. 4 \\
\hline Mujer & & & $\begin{array}{c}0,640^{* * *} \\
(0,0347)\end{array}$ & $\begin{array}{c}0,612 \\
(0,0326)\end{array}$ \\
\hline
\end{tabular}

Herencia en la cúspide

\begin{tabular}{lcccc} 
Constante & $2871,8^{* * *}$ & $1801,4^{* * * *}$ & $1629,5^{* * *}$ & $2018,5^{* * *}$ \\
& $(269,0)$ & $(199,7)$ & $(264,2)$ & $(297,7)$ \\
\hline R2 & 0,067 & 0,220 & 0,307 & 0,288 \\
Log-likelihood & $-798,1$ & $-737,2$ & $-696,5$ & $-705,7$ \\
BIC & 1642,0 & 1559,2 & 1491,0 & 1496,3 \\
N & 683 & 683 & 683 & 683 \\
\hline
\end{tabular}

Coeficientes exponenciados; errores estándar entre paréntesis. Fuente: elaboración propia con base en la Encuesta FONCYT 2012-2013. ${ }^{*} \mathrm{p}<0.10,{ }^{* *} \mathrm{p}<0.05,{ }^{* * *} \mathrm{p}<0.01$

senta una mejora respecto a la bondad de ajuste del modelo 3; sin embargo, permite observar algunas cuestiones pertinentes a los objetivos de este trabajo. Mientras que para la clase superior no se observan diferencias significativas en función de la pendiente de la trayectoria realizada (siempre respecto a la categoría de contraste), para el caso de las clases medias, la estabilidad de clase brindaría una mejora en los ingresos respecto a las trayectorias de ascenso y descenso hacia la misma.

Con referencia al acceso a la propiedad de la vivienda, se ha optado por realizar una regresión logística binomial (propiedad vs. no propiedad) para cada uno de los modelos. En el cuadro 7 se presentan los coeficientes, expresados en odds ratios, para cada categoría y las medidas de bondad de ajuste.

A diferencia del análisis sobre el nivel de ingresos, los cuatro modelos ahora puestos a prueba no presentan un buen ajuste. Mientras que para las carac- terísticas de origen no puede aseverarse la existencia de una influencia relevante de las mismas sobre el acceso a la propiedad, al igual que lo sucedido con los ingresos, dicho efecto se transmite vía mediación de clase o nivel educativo. Sin embargo, aun realizando un control a partir de las características adquiridas (modelo 2), los efectos directos de la clase de origen se mantienen con una brecha de entre el 75 $\%$ y el $60 \%$ para individuos con origen en las clases medias y la clase trabajadora calificada vs. aquellos con orígenes en la clase trabajadora no calificada. Este persistente efecto directo de origen pudiera estar haciendo referencia a transferencias vía herencia y donaciones, desde posiciones en que se han podido acumular activos patrimoniales en períodos anteriores para luego ser transferidos a sus hijos e hijas (Torche y Spilerman 2006), o a aspectos de la socialización de personas que crecieron en contextos en los cuales los padres eran propietarios de la vivienda (Torche y Spilerman 2009, 94). 
Cuadro 7.

Regresión logística binomial. Variable dependiente: propiedad de la vivienda. CABA 2012-2013+

\begin{tabular}{|c|c|c|c|c|}
\hline & Mod. 1 & Mod. 2 & Mod. 3 & Mod. 4 \\
\hline \multirow[t]{2}{*}{ Clase directiva-profesional (origen) } & $2,048^{* *}$ & 1,458 & 1,319 & \\
\hline & $(0,713)$ & $(0,540)$ & $(0,501)$ & \\
\hline \multirow[t]{2}{*}{ Pequeña burguesía (origen) } & $2,401^{+* * *}$ & $1,756^{*}$ & 1,692 & \\
\hline & $(0,713)$ & $(0,553)$ & $(0,546)$ & \\
\hline \multirow[t]{2}{*}{ Clase media rutinaria-técnica (origen) } & $2,100^{* *}$ & $1,703^{*}$ & 1,530 & \\
\hline & $(0,626)$ & $(0,537)$ & $(0,497)$ & \\
\hline \multirow[t]{2}{*}{ Clase obrera calificada (origen) } & $1,632^{*}$ & $1,608^{*}$ & 1,365 & \\
\hline & $(0,440)$ & $(0,449)$ & $(0,394)$ & \\
\hline \multirow[t]{2}{*}{ Clase obrera no calificada (origen) } & Ref. & Ref. & Ref. & \\
\hline & $()$. & $()$. & $()$. & \\
\hline \multirow[t]{2}{*}{ Hasta primario completo (origen) } & Ref. & Ref. & Ref. & Ref. \\
\hline & $()$. & $()$. & $()$. & $()$. \\
\hline \multirow[t]{2}{*}{ Hasta secundario completo (origen) } & 1,090 & 0,939 & 1,154 & 1,074 \\
\hline & $(0,194)$ & $(0,188)$ & $(0,241)$ & $(0,218)$ \\
\hline \multirow[t]{2}{*}{ Hasta universitario completo (origen) } & 0,809 & $0,632^{*}$ & 0,844 & 0,786 \\
\hline & $(0,203)$ & $(0,170)$ & $(0,237)$ & $(0,218)$ \\
\hline \multirow[t]{2}{*}{ Clase directiva-profesional } & & $2,761^{* * *}$ & $2,189^{* *}$ & \\
\hline & & $(0,988)$ & $(0,816)$ & \\
\hline \multirow[t]{2}{*}{ Pequeña burguesía } & & $1,895^{* *}$ & $1,810^{*}$ & \\
\hline & & $(0,605)$ & $(0,597)$ & \\
\hline \multirow[t]{2}{*}{ Clase media rutinaria-técnica } & & 1,339 & 1,295 & \\
\hline & & $(0,400)$ & $(0,399)$ & \\
\hline \multirow[t]{2}{*}{ Clase obrera calificada } & & 0,699 & 0,718 & \\
\hline & & $(0,186)$ & $(0,202)$ & \\
\hline \multirow[t]{2}{*}{ Clase obrera no calificada } & & Ref. & Ref. & \\
\hline & & $()$. & $()$. & \\
\hline \multirow[t]{2}{*}{ Hasta primario completo } & & Ref. & Ref. & Ref. \\
\hline & & $()$. & $()$. & (.) \\
\hline \multirow[t]{2}{*}{ Hasta secundario completo } & & 1,301 & 1,402 & 1,406 \\
\hline & & $(0,334)$ & $(0,370)$ & $(0,367)$ \\
\hline \multirow[t]{2}{*}{ Hasta universitario completo } & & 1,136 & 1,369 & 1,302 \\
\hline & & $(0,340)$ & $(0,422)$ & $(0,396)$ \\
\hline \multirow[t]{2}{*}{ Edad } & & & $1,048^{* \star *}$ & $1,049^{* * *}$ \\
\hline & & & $(0,00867)$ & $(0,00861)$ \\
\hline \multirow[t]{2}{*}{ Varón } & & & Ref. & Ref. \\
\hline & & & $()$. & $()$. \\
\hline
\end{tabular}




\begin{tabular}{|c|c|c|c|c|}
\hline & Mod. 1 & Mod. 2 & Mod. 3 & Mod. 4 \\
\hline Mujer & & & $\begin{array}{c}1,209 \\
(0,206)\end{array}$ & $\begin{array}{c}1,228 \\
(0,202)\end{array}$ \\
\hline Herencia en la cúspide & & & & $\begin{array}{l}3,352^{* *} \\
(1,644)\end{array}$ \\
\hline Ascenso a la cúspide & & & & $\begin{array}{l}3,195^{4 * *} \\
(1,133)\end{array}$ \\
\hline Descenso a la clase media & & & & $\begin{array}{l}2,064^{*} \\
(0,799)\end{array}$ \\
\hline Herencia en la clase media & & & & $\begin{array}{l}2,380^{*+*} \\
(0,648)\end{array}$ \\
\hline Ascenso a la clase media & & & & $\begin{array}{l}1,691^{*} \\
(0,462)\end{array}$ \\
\hline Descenso a la clase trabajadora & & & & $\begin{array}{c}1,077 \\
(0,308)\end{array}$ \\
\hline Herencia en la clase trabajadora & & & & $\begin{array}{l}\text { Ref. } \\
(.)\end{array}$ \\
\hline Constante & $\begin{array}{c}0,708 \\
(0,172)\end{array}$ & $\begin{array}{c}0,606 \\
(0,191)\end{array}$ & $\begin{array}{l}0,0596^{* * *} \\
(0,0311)\end{array}$ & $\begin{array}{l}0,0626^{* * *} \\
(0,0296)\end{array}$ \\
\hline PseudoR2 & 0,012 & 0,043 & 0,080 & 0,076 \\
\hline Log-likelihood & $-465,9$ & $-451,7$ & $-433,8$ & $-435,9$ \\
\hline $\mathrm{BIC}$ & 977,6 & 988,3 & 965,6 & 956,8 \\
\hline $\mathrm{N}$ & 688 & 688 & 688 & 688 \\
\hline
\end{tabular}

Coeficientes exponenciados; errores estándar entre paréntesis.

Fuente: elaboración propia con base en la Encuesta FONCYT 2012-2013.

+ Para todos los modelos, se ha realizado la prueba Hosmer Lemeshow y los valores de significatividad superaron el 0,05.

${ }^{*} p<0.10,{ }^{* *} p<0.05,{ }^{* * *} p<0.01$

Ahora bien, centrándose en la clase de destino, las probabilidades de ser propietario de una vivienda aumentan aproximadamente el doble para aquellos individuos que pertenecen a la clase directiva-profesional y pequeña burguesía respecto a aquellos peores posicionados. Esta relación se específica al considerar conjuntamente los orígenes y los destinos de clase, bajo el formato de trayectorias (modelo 4). En este sentido, los orígenes cuentan, en la medida en que aquellos individuos con orígenes en la clase directiva-profesional presentan mejores condiciones de acceso a la vivienda frente a aquellos que provienen del resto de las clases. Similar situación se presenta para aquellos que descienden o provienen de las clases medias, frente a aquellos que tienen orígenes en la clase trabajadora.

Por otra parte, es válido señalar que, para el estudio de este tipo de temática, dos efectos deben ser considerados y controlados (Kurz y Blossfeld 2004:
14; Torche y Spilerman 2009: 96): la cohorte y el curso de vida. Si bien ambos están correlacionados y pueden ser medidos por el mismo indicador, el primero refiere en mayor medida a los contextos históricos que signan a cada una de las generaciones, mientras que el segundo da cuenta de los procesos demográficos, ocupacionales, vitales, etc. por los que transitan los sujetos a lo largo de su vida. En este caso, a través del control por edad puede observarse que cada año adicional con el que cuentan los individuos implica un $5 \%$ más de probabilidad de acceso a la propiedad de la vivienda. De este modo, esta mayor desigualdad evidenciada entre los jóvenes adultos y los adultos puede explicarse por una mayor permanencia de los jóvenes en el sistema educativo, la mayor dificultad para conseguir un empleo estable y de calidad o la dificultad presentada en los últimos años para el acceso al crédito hipotecario, entre otros. 
Finalmente, para medir los efectos de los factores de origen y destino sobre el tercer aspecto considerado como parte constituyente del bienestar material, el nivel de consumo, se presenta la siguiente regresión lineal múltiple, que tiene como variable dependiente el índice factorial anteriormente explicitado (cuadro 8).

Al medir la desigualdad de acceso al consumo nos encontramos con efectos similares a los hallados para el caso del nivel de ingreso, aunque de menor magnitud. Vale recordar que diferentes investigadores optan por trabajar con el consumo de bienes durables, ya que permiten una mejor aproximación al "ingreso permanente" de los hogares (Filmer y Pritchett 2001; McKenzie 2005; Minujin y Bang 2002). Al igual que en los modelos anteriores, los efectos de origen directos se mediatizan al incorporar el control de clase social, nivel educativo, sexo y edad. Sin em- bargo, los orígenes en la pequeña burguesía (hijos e hijas de pequeños propietarios de establecimientos o trabajadores independientes calificados) mantienen sus efectos, aun al ser controlados. Como bien señalan Torche y Spilerman (2009: 92) para el caso mexicano, esto podría significar que la influencia de los padres sobre el nivel de consumo material de los hijos e hijas puede darse de forma indirecta, a partir de inversiones educativas o procesos de movilidad ocupacional. Al incorporar la clase social y el nivel educativo de la persona encuestada, los efectos se comportan de manera esperada: a mejor posición, mayor nivel de consumo material. Teniendo en cuenta el BIC, los modelos 2 y 4 presentan un ajuste más parsimonioso, descartando la influencia del sexo y la edad en el primer caso y considerando la trayectoria de movilidad en el segundo.

\section{Cuadro 8.}

Regresión lineal múltiple. Variable dependiente: índice de bienes. CABA 2012-2013

\begin{tabular}{|c|c|c|c|c|}
\hline & Mod. 1 & Mod. 2 & Mod. 3 & Mod. 4 \\
\hline \multirow[t]{2}{*}{ Clase directiva-profesional (origen) } & $0,0709^{* * *}$ & 0,0146 & 0,0129 & \\
\hline & $(0,0236)$ & $(0,0236)$ & $(0,0236)$ & \\
\hline \multirow[t]{2}{*}{ Pequeña burguesía (origen) } & $0,0886^{* * *}$ & $0,0422^{* *}$ & $0,0396^{* *}$ & \\
\hline & $(0,0200)$ & $(0,0199)$ & $(0,0199)$ & \\
\hline \multirow[t]{2}{*}{ Clase media rutinaria-técnica (origen) } & $0,0530^{* * *}$ & 0,0118 & 0,00645 & \\
\hline & $(0,0202)$ & $(0,0200)$ & $(0,0201)$ & \\
\hline \multirow[t]{2}{*}{ Clase obrera calificada (origen) } & 0,0150 & $-0,000227$ & $-0,00406$ & \\
\hline & $(0,0183)$ & $(0,0178)$ & $(0,0179)$ & \\
\hline \multirow[t]{2}{*}{ Clase obrera no calificada (origen) } & Ref. & Ref. & Ref. & \\
\hline & $()$. & (.) & (.) & \\
\hline \multirow[t]{2}{*}{ Hasta primario completo (origen) } & Ref. & Ref. & Ref. & Ref. \\
\hline & (.) & (.) & (.) & $()$. \\
\hline \multirow[t]{2}{*}{ Hasta secundario completo (origen) } & $0,0418^{* * *}$ & 0,0115 & 0,0140 & 0,0108 \\
\hline & $(0,0120)$ & $(0,0126)$ & $(0,0127)$ & $(0,0125)$ \\
\hline \multirow[t]{2}{*}{ Hasta universitario completo (origen) } & $0,0354^{* *}$ & 0,00412 & 0,00700 & $-0,00130$ \\
\hline & $(0,0171)$ & $(0,0170)$ & $(0,0172)$ & $(0,0171)$ \\
\hline \multirow[t]{2}{*}{ Clase directiva-profesional } & & $0,0989^{* * *}$ & $0,0896^{* * *}$ & \\
\hline & & $(0,0224)$ & $(0,0227)$ & \\
\hline \multirow[t]{2}{*}{ Pequeña burguesía } & & $0,0828^{* * *}$ & $0,0766^{* * *}$ & \\
\hline & & $(0,0203)$ & $(0,0204)$ & \\
\hline \multirow[t]{2}{*}{ Clase media rutinaria-técnica } & & $0,0622^{* * *}$ & $0,0592^{* * *}$ & \\
\hline & & $(0,0193)$ & $(0,0193)$ & \\
\hline
\end{tabular}


Clase obrera calificada

$\begin{array}{cc}0,0256 & 0,0168 \\ (0,0173) & (0,0176)\end{array}$

Clase obrera no calificada

Ref. Ref.

(.) (.)

Hasta primario completo

Ref.

Ref.

Ref.

(.)

(.)

(.)

Hasta secundario completo

$\begin{array}{lll}0,0469^{* * *} & 0,0470^{* * *} & 0,0485^{* * *} \\ (0,0165) & (0,0165) & (0,0164)\end{array}$

Hasta universitario completo

$0,0734^{* * *}$

$0,0770^{* * * *} \quad 0,0765^{* * * *}$

$(0,0192)$

$(0,0192)$

$(0,0192)$

Edad

$0,000412 \quad 0,000313$

$(0,000488) \quad(0,000487)$

Varón

Ref.

Ref.

(.)

Mujer

Herencia en la cúspide

Ascenso a la cúspide

Descenso a la clase media

Herencia en la clase media

Ascenso a la clase media

\begin{tabular}{lcccc} 
Constante & $0,497^{*+*}$ & $0,437^{*+*}$ & $0,436^{*+*}$ & $0,449^{* * *}$ \\
& $(0,0165)$ & $(0,0203)$ & $(0,0313)$ & $(0,0282)$ \\
\hline R2 & 0,085 & 0,172 & 0,180 & 0,170 \\
Log-likelihood & 391,6 & 426,0 & 429,0 & 425,2 \\
BIC & $-737,4$ & $-767,0$ & $-760,0$ & $-765,5$ \\
N & 688 & 688 & 688 & 688 \\
\hline
\end{tabular}

Errores estándar en paréntesis.

Fuente: elaboración propia en base a Encuesta FONCYT 2012-2013.

${ }^{*} p<0.10,{ }^{* *} p<0.05,{ }^{* * *} p<0.01$ 


\section{Discusión Y CONCLUSIONES}

Este trabajo tiene como objetivo central indagar acerca de la relación existente entre los procesos de estructuración de clase y la existencia de desiguales condiciones de vida. En este sentido, el propósito que motivó dicha empresa fue doble. Por un lado, se intentó combinar dos tradiciones sociológicas: el análisis de clase y el estudio de la movilidad social. Por otra parte, se buscaron respuestas a cuestiones que han quedado irresueltas o no han sido abordadas en el campo de la movilidad social. Comprender el modo en el que las desigualdades de condiciones, de oportunidades y de resultados se vinculan y refuerzan es un posible camino para continuar en este campo de investigación.

Tanto el análisis descriptivo enfocado en la estructura de clases como el análisis multidimensional han coincidido en mostrar ciertas tendencias. La posición de clase del hijo o hija es la variable que explica, en mayor medida, las diferencias tanto de ingresos como de consumo y acceso a la propiedad de la vivienda. Principalmente, esta relación se da con mayor intensidad al analizar los niveles de ingresos $y$, con menor fuerza, en el caso de la vivienda.

En segundo lugar, siguiendo la tendencia evidenciada en otros trabajos para otros contextos (Erikson y Jonsson 1998; Torche y Costa Ribeiro 2012; Torche y Spilerman 2009; Jencks 1979; Fachelli y Torrents 2018), los efectos directos del origen social son mayormente débiles para las tres variables de bienestar. En este sentido, dos explicaciones pueden arriesgarse. Por un lado, podría evidenciarse una cierta atenuación en las estrategias familiares impulsadas desde los orígenes sociales (movilización del capital social, socialización de expectativas, transferencias de recursos, etc.), más allá de la influencia ejercida en la búsqueda de una mejor posición social intergeneracional o en el sostenimiento de la reproducción de clase. En otras palabras, podría decirse que las condiciones impartidas por el origen de clase comienzan a perder su potencia estratificadora ante la aparición de otros procesos constituyentes de la desigualdad, como la posición ocupada en la estructura de clases. Dicha hipótesis podría sostenerse para varios ámbitos, tal como lo han demostrado las investigaciones anteriormente señaladas. Una segunda explicación daría cabida a la hipótesis planteada más arriba, que señalaba la posible influencia del contexto socio-económico de la ciudad (principalmente, oferta educativa de calidad y un mercado de trabajo dinámico), en tanto aspecto interviniente en la relación origen de clase-destino de clase-bienestar material. Para reforzar esta argumentación, sería necesario profundizar en estudios comparativos que consideren otras regiones del país. En ambos casos, el aporte sería significativo para el campo de la movilidad social, en la medida en que se evidencia cierta pérdida de potencia explicativa de los orígenes de clase frente a resultados (outcomes) que tienen entidad más allá de la posición de destino.

En tercer lugar, la incorporación de los controles por sexo y edad ha permitido ilustrar la amplia desventaja que sufren las mujeres en las probabilidades de acceder a mejores ingresos, así como la dificultad de los más jóvenes para ser propietarios de una vivienda. La incorporación de un modelo que considera los efectos de la trayectoria intergeneracional ha permitido matizar la influencia de la clase social sobre el bienestar, más allá del bajo nivel explicativo que ha demostrado el origen de clase. Teniendo en cuenta esto, para el caso de la clase superior, el carácter ascendente o de heredero introduciría cierta ventaja en favor de los segundos, principalmente respecto al nivel de consumo y el acceso a la vivienda. Por su parte, en el caso de las posiciones medias, puede sostenerse que los herederos presentan mejores condiciones de acceso al bienestar material respecto a los descendentes de dicha clase y, principalmente, frente a los ascendentes.

Finalmente, puede señalarse que, si bien este artículo ha logrado, en concordancia con otros trabajos realizados para otros contextos sociales y sobre otros aspectos del bienestar, dar cuenta de ciertas regularidades estadísticamente desarrolladas (fuerte peso de la posición de clase en la distribución del bienestar, aunque con una leve influencia del origen de clase), aún es una deuda pendiente en las investigaciones sobre estratificación y movilidad social el esclarecimiento de los mecanismos causales que constituyen los nexos y fundamentos de los procesos revisados. Como bien lo ha planteado Goldthorpe (2017), mientras que una estrategia puede estar orientada a la revisión analítica del catálogo de mecanismos teóricamente fundamentados, otras deben intentarse a partir de la aplicación de distintos métodos que puedan "determinar mejor la operación real de los mecanismos causales o procesos sociales que subyacen" (Cox 1992, en Goldthorpe 2017: 108).

\section{Agradecimientos}

Este artículo fue elaborado en el contexto de la red INCASI, un proyecto que ha recibido financiamiento del programa de la Unión Europea de investigación e innovación Horizonte 2020 (Marie Skłodowska-Curie GA N. ${ }^{\circ} 691004$ ) y que es coordinado por el Dr. Pedro López-Roldán. El mismo refleja únicamente la mirada del autor y la agencia no es responsable por el uso que pueda hacerse de la información que contiene. Así mismo, se agradece el financiamiento brindado por el Consejo Nacional de Investigaciones Científicas y Técnicas (CONICET) y al Fondo para la Investigación Científica y Tecnológica (FONCYT), que mediante el Proyecto PICT 2011-2189 ha permitido la elaboración de la fuente de información utilizada. 


\section{NOTAS}

[1] A esta lista deben agregarse los importantes aportes desde la sociología francesa de autores como Bourdieu (2012), Bertaux (1994), Bertaux y Thompson (2006) y Boudon (1983).

[2] En 2012, para la población ocupada mayor de 30 años, la CABA mostraba un $44 \%$ de población con nivel educativo superior completo, mientras que el AGBA en su totalidad alcanzaba un $25 \%$.

[3] Esto no implica desconocer un proceso de desigualdad previo o, al menos, paralelo, que es aquella ferente al "derecho a la ciudad" (Oszlak 1991), principalmente regulado por la esfera del mercado.

[4] Realizada a través del proyecto FONCyT Tendencias y transformaciones en la estructura social: El impacto de los procesos de movilidad social en los horizontes de consumo y la participación política. Un análisis de la Región Metropolitana de Buenos Aires. 2003 - 2011, coordinado por el Dr. Eduardo Chávez Molina del Instituto de Investigaciones Gino Germani, UBA.

[5] El percentil 95 se corresponde con la edad de 63 años. Es decir, que la población considerada, en mayor medida, ha nacido entre los años 1950 y 1983.

\section{RefERENCIAS BibliográficAS}

Albertini, M. 2013. "The relation between social class and economic inequality: A strengthening or weakening nexus? Evidence from the last three decades of inequality in Italy". Research in Social Stratification and Mobility 33: 27-39. https://doi.org/10.1016/j.rssm.2013.05.001

Baranger, D. 2009. "Construcción y análisis de datos. Introducción al uso de técnicas cuantitativas en la investigación social". Consultado: 23/8/2016. https://bit. ly/2fzyZ3S

Beccaria, L. A. 1978. "Una contribución al estudio de la movilidad social en la Argentina. Análisis de los resultados de una encuesta para el Gran Buenos Aires". Desarrollo económico 17(68): 593-618. https://doi. org/10.2307/3466410

Behrman, J. R. y V. Vélez-Grajales. 2015. "Intergenerational mobility patterns for schooling, occupation and household wealth: the case of México". México DF: Centro de Estudios Espinosa Yglesias.

Benza, G. 2012. "Estructura de clases y movilidad intergeneracional en Buenos Aires: ¿el fin de una sociedad de 'amplias clases medias'?". Tesis de doctorado, El Colegio de México, Centro de Estudios Sociológicos, México.

Benza, G. 2016. "La estructura de clases durante la década 2003-2013". Pp. 111-140, en La sociedad argentina hoy. Radiografía de una nueva estructura. Buenos Aires: Siglo XXI Editores.

Bertaux, D. 1994. "Genealogías sociales comentadas y comparadas. Una propuesta metodológica". Estudios sobre las culturas contemporáneas 6 (17): 333-349.

Bertaux, D. y P. R. Thompson. 2006. Pathways to social class: A qualitative approach to social mobility. New Jersey: Transaction Publishers.

Blau, P. M., y O. D. Duncan. 1967. The American occupational structure. New York: John Wiley \& Sons.

Boltvinik, J. 2014. "América Latina, de la vanguardia al rezago en medición multidimensional de la pobreza". Pp. 23-74 en Multidimensionalidad de la pobreza. Ciudad de Buenos Aires: CLACSO.
[6] De este modo, el exponencial del coeficiente beta de una regresión representa el porcentaje de cambio en la variable dependiente asociado al cambio de unidad en la variable independiente.

[7] Vale aclarar que, una vez calculados los puntajes para cada uno de los casos encuestados, se realizó una transformación en el valor final de los mismos, para que oscilen entre 0 y 1 y, de este modo, facilitar la lectura.

[8] Se ha decidido retirar del cuarto modelo las variables de clase de origen y destino, con el propósito de eliminar la posible colinealidad existente entre algunas categorías de dichas variables y aquellas de la variable 'trayectoria'. Así mismo, se optó por la incorporación de dicha variable en lugar de la aplicación de interacciones (entre la clase de origen y de destino), debido al bajo nivel de significatividad estadísica evidenciado en las mismas.

[9] Cabe recordar que la edad mínima relevada en la encuesta utilizada es de 30 años.

Boudon, R. 1983. La desigualdad de oportunidades. La movilidad social en las sociedades industriales. Barcelona: Laia.

Bourdieu, P. 2000. Las estructuras sociales de la economía. Buenos Aires: Manantial.

Bourdieu, P. 2012. La Distinción: criterios y bases sociales del gusto. Buenos Aires: Taurus.

Cachón Rodríguez, L. 1989. ¿Movilidad social o trayectorias de clase?: elementos para una crítica de la sociología de la movilidad social. Madrid: Centro de Investigaciones Sociológicas (CIS). http://dialnet.unirioja.es/ servlet/libro?codigo $=132862$

Carabaña, J. 1997. "Esquemas y estructuras". Revista crítica de ciências sociais $\mathrm{N} .^{\circ}$ 49: 67-91.

Chávez Molina, E. 2013. Desigualdad y movilidad social en el mundo contemporáneo. Buenos Aires: Miño y Dávila.

Chávez Molina, E. y N. Sacco. 2015. "Reconfiguraciones en la estructura social: dos décadas de cambios en los procesos distributivos". PP. 287-312 en Hora de Balance: Proceso de acumulación, mercado de trabajo y bienestar. Argentina, 2002-2014. Buenos Aires: Eudeba.

Dalle, P. 2016. Movilidad social desde las clases populares: un estudio sociológico en el Área Metropolitana de Buenos Aires 1960-2013. IIGG-CLACSO.

Del Cueto, C. M. y M. Luzzi. 2016. "Salir a comprar. El consumo y la estructura social en la Argentina reciente." Pp. 209-232 en La sociedad argentina hoy. Radiografía de una nueva estructura. Buenos Aires: Siglo XXI Editores.

Dubet, F. 2015. "Clases sociales y descripción de la sociedad". Revista Ensambles 3: 184-190.

Erikson, R. y J. H. Goldthorpe. 1992. The constant flux: A study of class mobility in industrial societies. Oxford University Press, USA.

Erikson, R. y J. H. Goldthorpe. 2002. "Intergenerational inequality: A sociological perspective". The Journal of Economic Perspectives 16 (3): 31-44. https://doi. org/10.1257/089533002760278695 
Erikson, R. y J. O. Jonsson. 1998. "Social origin as an interest-bearing asset: Family background and labour-market rewards among employees in Sweden". Acta Sociologica 41 (1): 19-36. https://doi. org/10.1177/000169939804100102

Esping-Andersen, G. 2004. "Untying the Gordian Knot of Social Inheritance". Research in Social Stratification and Mobility 21: 115-138. https://doi.org/10.1016/S02765624(04)21007-1

Fachelli, S. 2013. “¿La crisis aumenta las diferencias entre estratos sociales?: la medición del cambio social en $\mathrm{Ar}$ gentina". Empiria. Revista de metodología de ciencias sociales 25: 13-46. http://e-spacio.uned.es/fez/eserv/ bibliuned:Empiria-2013-25-6000/Documento.pdf

Fachelli, S. y D. Torrents. 2018. "Comparison of the Effect of Social Background on the Wages of Spanish Graduates before and during a Crisis Context". International Journal of Sociology of Education 7 (2): 154-180. https://doi.org/10.17583/rise.2018.3210

Filmer, D. y L. H. Pritchett. 2001. "Estimating Wealth Effects without Expenditure Data-or Tears: An Application to Educational Enrollments in States of India". Demography 38 (1): 115-132. https://doi.org/10.2307/3088292

Germani, G. 1955. Estructura social de la Argentina: Análisis estadístico. Buenos Aires: Solar.

Germani, G. 1963. "La movilidad social en la Argentina". Pp 317 - 365 en Movilidad social en la sociedad industrial, de Seymour Martin Lipset y Reinhard Bendix. Buenos Aires: EUDEBA.

Giddens, A. 1994. Consecuencias de la modernidad. Madrid: Alianza Editorial.

Giddens, A. 2001. La tercera vía y sus críticos. Madrid: Grupo Santillana de Ediciones SA.

Glass, D. y J. Hall. 1954. "Social Mobility in Britain: A Study of Inter-Generation Changes in Status". Pp 177-217 en Social Mobility in Britain: A study of inter-generation changes in status, de D. Glass. Londres: Routledge and Kegan Paul.

Goldthorpe, J. H. 2010. De la sociología: números, narrativas e integración de la investigación y la teoría. Madrid: CIS.

Goldthorpe, J. H. 2017. La sociología como ciencia de la población. Madrid: Alianza Editorial.

Gómez Rojas, G. 2009. "Estratificación social, hogares y género: incorporando a las mujeres". Tesis de Doctorado, Facultad de Ciencias Sociales, Universidad de Buenos Aires. Inédito. Consultado en la Biblioteca Norberto Rodríguez Bustamante.

Harding, D. J., C. Jencks, L. M. Lopoo y S. E. Mayer. 2004. "The changing effect of family background on the incomes of American adults". Consultado 6/10/2016. http://papers. ssrn.com/sol3/papers.cfm?abstract_id $=478461$

Hauser, R. M. y W. H. Sewell. 1986. "Family effects in simple models of education, occupational status, and earnings: Findings from the Wisconsin and Kalamazoo studies". Journal of Labor Economics 4 (3): S83-S115. https://doi.org/10.1086/298122

Herrera-Usagre, M. 2013. "La transmisión intergeneracional de aptitudes y actitudes culturales. Adaptando el paradigma de la omnivoridad cultural para Andalucía". Revista Internacional de Sociología 71 (1): 143-67. https://doi.org/10.3989/ris.2011.11.25

Hout, M. y T. A. DiPrete. 2006. "What we have learned: RC28's contributions to knowledge about social stratification". Research in Social Stratification and Mobility 24 (1): 1-20. https://doi.org/10.1016/j.rssm.2005.10.001
INDEC. 2003. ¿Qué es el gran Buenos Aires?. Buenos Aires: INDEC.

Jencks, C. 1979. Who gets ahead? The determinants of economic success in America. New York: Basic Books.

Jorrat, J. R. 1987. "Exploraciones sobre movilidad ocupacional intergeneracional masculina en el Gran Buenos Aires". Desarrollo Económico 27: 261-278.

Jorrat, J. R. 2000. Estratificación social y movilidad: un estudio del área metropolitana de Buenos Aires. Universidad Nacional de Tucumán, Secretaría de Ciencia y Técnica.

Kemeny, J. 2013. Housing and Social Theory. Hoboken: Taylor and Francis.

Kerbo, H. R. 1998. Estratificación social y desigualdad: el conflicto de clases en perspectiva histórica y comparada. Madrid: McGraw-Hill Interamericana de España.

Kessler, G. y V. Espinoza. 2007. "Movilidad social y trayectorias ocupacionales en Argentina: rupturas y algunas paradojas del caso de Buenos Aires". Pp. 473-502 en Estratificación y movilidad social en América Latina: transformaciones estructurales de un cuarto de siglo, editado por $\mathrm{R}$. Atria, A. León, y R. Franco. Santiago de Chile: CEPAL.

Kurz, K. 2004. "Labour Market Position, Intergenerational Transfers and Home-ownership A Longitudinal Analysis for West German Birth Cohorts". European Sociological Review 20 (2): 141-159. https://doi.org/10.1093/ esr/jch009

Kurz, K. y H. P. Blossfeld. 2004. Home ownership and social inequality in comparative perspective. Studies in social inequality. Stanford, Calif: Stanford University Press.

Le Roux, B., H. Rouanet, M. Savage y A. Warde. 2008. "Class and cultural division in the UK". Sociology 42 (6): 10491071. https://doi.org/10.1177/0038038508096933

Lersch, P. M. y R. Luijkx. 2015. “Intergenerational Transmission of Homeownership in Europe: Revisiting the Socialisation Hypothesis". Social Science Research 49: 327 342. https://doi.org/10.1016/j.ssresearch.2014.08.010

Lipset, S. M. y R. Bendix. 1963. La movilidad social en la sociedad industrial. Buenos Aires: Eudeba.

McKenzie, D. J. 2005. "Measuring inequality with asset indicators". Journal of Population Economics 18 (2): 229260. https://doi.org/10.1007/s00148-005-0224-7

Miller, S. M. 1960. "Comparative social mobility". Current Sociology 9 (1): 1-61.

Minujin, A. y J. H. Bang. 2002. "Indicadores de inequidad social. Acerca del uso del "índice de bienes" para la distribución de los hogares". Desarrollo Económico 42 (165): 129-146. https://doi.org/10.2307/3455980

Oszlak, O. 1991. Merecer la ciudad: los pobres y el derecho al espacio urbano. Buenos Aires: Cedes.

Parsons, T. 1954. Ensayos de teoría sociológica. Buenos Aires: Paidós.

Pena-Trapero, B. 2009. "La medición del bienestar social: una revisión crítica". Estudios de Economía aplicada 27 (2): 299-324. http://www.redalyc.org/articulo. oa? id=30117056001

Pla, J. 2014. "Consumo y trayectorias de clase. Distinción y competencia en el abordaje de los procesos de estratificación." Question 1 (43): 311-327.

Pla, J. 2016. Condiciones objetivas y esperanzas subjetivas. Movilidad social y marcos de (in)certidumbre. Un abordaje multidimensional de las trayectorias de clase. Argentina durante la primera década del siglo XXI. Buenos Aires: Editorial Autores de Argentina. 
Quartulli, D. y A. Salvia. 2012. "La movilidad y la estratificación socio-ocupacional en la Argentina. Un análisis de las desigualdades de origen". Entramados y Perspectivas, № 2: 15-42.

Rawls, J. 1995. Teoría de la justicia. México DF: Fondo de Cultura Económica.

Reyes-Hernández, M. S., J. A. Cerón-Vargas y M. LópezLópez. 2016. "México: un país que no se mueve. un análisis de movilidad social a partir de un enfoque de clases". Panorama económico 12 (23): 87-122. https:// doi.org/10.29201/pe-ipn.v12i23.104

Reygadas, L. 2004. "Las redes de la desigualdad: un enfoque multidimensional". Política y cultura 22: 7-25.

Riveiro, M. 2011. "Los ángeles no tienen sexo. La movilidad social sí". Ponencia presentada en II Seminario Internacional Movilidad y Cambio Social en América Latina, 4 y 5 de noviembre, Mar del Plata.

Roemer, J. E. y A. Trannoy. 2016. "Equality of opportunity: Theory and measurement". Journal of Economic Literature 54 (4): 1288-1332. https://doi.org/10.1257/ jel.20151206

Rodríguez de la Fuente, J. 2014. "La movilidad social en el espacio multidimensional : Ciudad Autónoma de Buenos Aires 2012-2013". Consultado 2/03/2016. https://ddd. uab.cat/record/137800

Rodríguez de la Fuente, J. 2016. "La movilidad social en el espacio multidimensional. CABA 2012-2013.”. Ponencia presentada en las IX Jornadas de Sociología de la UNLP, 5,6 y 7 de Diciembre, La Plata.

Rodríguez de la Fuente, J. y M. C. Fernández Melián. 2015. "Las trayectorias intergeneracionales de clase en el espacio social. Un abordaje multidimensional de la movilidad social. Ciudad Autónoma de Buenos Aires, 20122013.". Ponencia presentada en III Congreso Uruguayo de Sociología, 15, 16 y 17 de Julio, Montevideo.

Rubinstein, J. C. 1973. Movilidad social en una sociedad dependiente. Buenos Aires: Corregidor.

Sacco, N. 2016. "Las clases sociales en la Argentina según los censos de población de 1991 y 2001". Revista Argentina de Estadística Aplicada 3.

Sassen, S. 1998. "Ciudades en la economía global: enfoques teóricos y metodológicos". EURE 24 (71): 5-25.

Saunders, P. 1978. "Domestic property and social class". International Journal of Urban and Regional Research 2 (1-4): 233251. https://doi.org/10.1111/j.1468-2427.1978.tb00749.x

Saunders, P. 1984. "Beyond housing classes: the sociological significance of private property rights in means of consumption". International Journal of Urban and regional research 8 (2): 202-227. https://doi. org/10.1111/j.1468-2427.1984.tb00608.x

Savage, M., P. Watt y S. Arber. 1992. "Social Class, Consumption Divisions and Housing Mobility". Pp. 52-70 en Consumption and Class. Divisions and Change, editado por R. Burrows y C. Marsh. London: Palgrave Macmillan.

Sen, A. 1992. Nuevo examen de la desigualdad. Madrid: Alianza Editorial.

Spilerman, S. 2000. "Wealth and stratification processes". Annual Review of Sociology 26 (1): 497-524. https:// doi.org/10.1146/annurev.soc.26.1.497

Spilerman, S. y F. C. Wolff. 2012. "Parental wealth and resource transfers: How they matter in France for home ownership and living standards". Social Science Research 41 (2): 207-223. https://doi.org/10.1016/j.ssresearch.2011.08.002

Torche, F. y C. Costa-Ribeiro. 2012. "Parental Wealth and Children's Outcomes over the Life-Course in Brazil: A Propensity Score Matching Analysis". Research in Social Stratification and Mobility 30 (1): 79-96. https://doi. org/10.1016/j.rssm.2011.07.002

Torche, F. y S. Spilerman. 2006. Household Wealth in Latin America. 2006/114. Research Paper UNU-WIDER, United Nations University (UNU). https://www.econstor.eu/handle/10419/63394

Torche, F. y S. Spilerman. 2009. "Intergenerational influences of wealth in Mexico". Latin American Research Review 44 (3): 75-101. https://doi.org/10.1353/lar.0.0089

Torrado, S. 1992. Estructura social de la Argentina, 19451983. Buenos Aires: Ediciones de la Flor.

Torrado, S. 1998. "La medición empírica de las clases sociales". Pp 223-239 en Familia y diferenciación social. Buenos Aires: Eudeba.

Treiman, D. J. y H. B. G. Ganzeboom. 2000. "The fourth generation of comparative stratification research". Pp. 122150 enthe international handbook of sociology.

Van Eijck, K. 1999. "Socialization, education, and lifestyle: How social mobility increases the cultural heterogeneity of status groups". Poetics 26 (5-6): 309-328. https:// doi.org/10.1016/S0304-422X(99)00008-X

Velázquez, G. 2007. "Población, territorio y calidad de vida". Pp 573-600 en Población y bienestar en la Argentina del primero al segundo Centenario, compilado por $\mathrm{S}$. Torrado. Buenos Aires: Edhasa.

Warde, A. y M. Gayo-Cal. 2009. "The Anatomy of Cultural Omnivorousness: The Case of the United Kingdom". Poetics 37 (2): 119-145. https://doi.org/10.1016/j.poetic.2008.12.001

Weeden, K. A., Y. M. Kim, M. Di Carlo y D. Grusky. 2007. "Social Class and Earnings Inequality". American Behavioral Scientist 50 (5): 702-736. https://doi. org/10.1177/0002764206295015

Wright, E. O. 1979. Class structure and income determination. New York: Academic Press.

JOSÉ JAVIER RODRÍGUEZ DE LA FUENTE es Licenciado en Sociología, Universidad de Buenos Aires (UBA). Candidato a Doctor en Ciencias Sociales, Facultad de Ciencias Sociales, UBA. Miembro del equipo de Investigación "Desigualdad y Movilidad Social", Instituto de Investigaciones Gino Germani, UBA. Sus temas de interés abarcan la problemática de la estratificación y la movilidad social, las desigualdades sociales y el bienestar. 


\section{Anexo}

Cuadro 9.

Principales estadísticos del Análisis de Correspondencias Múltiples

\begin{tabular}{|c|c|c|c|}
\hline Categorías & Coord.* & Sqcorr.** & Contrib.*** \\
\hline \multicolumn{4}{|l|}{ Tv Led } \\
\hline Sí & 0,981 & 0,78 & 0,036 \\
\hline No & $-0,922$ & 0,78 & 0,034 \\
\hline \multicolumn{4}{|l|}{ Notebook } \\
\hline Sí & 1,069 & 0,86 & 0,054 \\
\hline No & $-1,681$ & 0,86 & 0,084 \\
\hline \multicolumn{4}{|l|}{ Consola } \\
\hline Sí & 1,787 & 0,891 & 0,068 \\
\hline No & $-0,69$ & 0,891 & 0,026 \\
\hline \multicolumn{4}{|l|}{ Heladera } \\
\hline Sí & 0,25 & 0,875 & 0,004 \\
\hline No & $-3,696$ & 0,875 & 0,067 \\
\hline \multicolumn{4}{|l|}{ Celular } \\
\hline Sí & 0,178 & 0,91 & 0,002 \\
\hline No & $-3,918$ & 0,91 & 0,051 \\
\hline \multicolumn{4}{|l|}{ Internet } \\
\hline Sí & 0,676 & 0,833 & 0,028 \\
\hline No & $-2,852$ & 0,833 & 0,12 \\
\hline \multicolumn{4}{|l|}{ Cable } \\
\hline Sí & 0,388 & 0,869 & 0,01 \\
\hline No & $-2,815$ & 0,869 & 0,074 \\
\hline \multicolumn{4}{|l|}{ Bluray } \\
\hline Sí & 2,102 & 0,898 & 0,044 \\
\hline No & $-0,315$ & 0,898 & 0,007 \\
\hline \multicolumn{4}{|l|}{ Colchón } \\
\hline Sí & 0,23 & 0,811 & 0,004 \\
\hline No & $-1,786$ & 0,811 & 0,028 \\
\hline \multicolumn{4}{|c|}{ Aire acondicionado } \\
\hline Sí & 1,235 & 0,898 & 0,061 \\
\hline No & $-1,323$ & 0,898 & 0,065 \\
\hline \multicolumn{4}{|l|}{ Cocina } \\
\hline Sí & 0,1 & 0,66 & 0,001 \\
\hline No & $-4,928$ & 0,66 & 0,037 \\
\hline \multicolumn{4}{|c|}{ Acceso a crédito } \\
\hline Sí & 0,539 & 0,562 & 0,003 \\
\hline No & $-0,094$ & 0,562 & 0,001 \\
\hline \multicolumn{4}{|l|}{ Automóvil } \\
\hline Sí & 1,407 & 0,92 & 0,057 \\
\hline No & $-0,835$ & 0,92 & 0,034 \\
\hline
\end{tabular}

